\title{
Self-guided Tour APP Interface Design Based on User Experience
}

\author{
Hairong Long \\ Fashion Institute \\ Sichuan Normal University \\ Chengdu, Sichuan, China 610101
}

\author{
Wanyu Zhang* \\ Fashion Institute \\ Sichuan Normal University \\ Chengdu, Sichuan, China 610101
}

\begin{abstract}
With the expansion of Internet market and the advocacy of national policy, the factors influencing interface design are analyzed from the perspective of user experience in order to meet people's demand for tourism products in the rapidly growing Internet market as well as people's aesthetic and travel needs. The interface design factors are summarized as user factors, environmental factors and emotional factors, thereby the mobile phone APP user experience design model is constructed, and the application of interface design factors in self-guided APP user requirements, architecture design and prototype design. Taking "Self-Guided APP - YOYO" interface design as an example, the design planning and design implementation of APP interface design is completed and the feasibility of the APP interface design methods is verified.
\end{abstract}

Keywords-product design; interface design; user experience; self-guided tour; user needs

\section{INTRODUCTION}

With the advent of the era of big data, rapid economic development and changes in people's consumption habits, people pay more and more attention to their own spiritual life. With the raising of tourist boom, the public have also accepted and accustomed to the tourism and life service mobile phone APP. The constant development of information technology and the Internet is transforming technological innovation forms, and the people-oriented design is gaining more and more importance, the interface design has also attracted tremendous attention. From user functional requirements to aesthetic needs, the tourism and life service APP gradually focus on the user experience that is more humanized and easier to be accepted. [1-2]

\section{SELF-GUIDED TOUR APP AND INTERFACE DESIGN}

Tourist boom sweeps China. It is tourism and service industry that appear along with the tourist boom, and often there will be some drawbacks in these fast-growing industry. Taking the job of tourist guide as an example, tourist guide is the leader of a package tour, helping the tourists to plan routes and provide the logistical support. However, tourists are unfamiliar in that place, if a tourist guide is unqualified in terms of service quality, then they will face a difficult situation. On January 29, 2016, the national tourism working conference

Fund Project: This paper is funded by "College Students' Innovative and Entrepreneurial Training Plan" project of Sichuan Normal University, scientific research fund project of Sichuan Provincial Department of Education (14SB0014), Qiang research center topic of key research base of Sichuan Provincial Philosophy and Social Sciences (QXZ1605). was held in Haikou, it was pointed out in the meeting that: to conduct pilot reform, release freelance tourist guide, cancel the policy of "tourists shall be delegated by travel agencies", to broaden practicing ways for the tourist guides. [3] Under the protection of policy, the governments in some areas have proposed the new concept of "booking tourist guide online" using C2C model, which has not only guaranteed tourists' traveling quality, but has regulated tourist guides' behavior. Thus, self-guided tour APP emerges. Interface design is an important part of Internet product design. With the continuous development and updating of Internet technology, people have proposed new requirements for the interface design of Internet products. For the self-guided tour APP interface design, the method to realize good user experience is to meet customer needs, emphasize the interactive interface and enhanced user emotion.

\section{ANALYSIS OF FACTORS INFLUENCING SELF-GUIDED TOUR APP INTERFACE DESIGN}

Self-guided tour APP is the tourism and life service APP taking tourists as the users, to meet the travel needs of tourists and resolve the problem of having no guides. The general travel life can be divided into three categories: function interface, emotion interface and environment interface. [4] It can be seen from the investigation of tourism and life service APP users' data that, the factors that influence self-guided tour APP interface design mainly reflect in the following aspects

\section{A. User}

Due to the excessive competition in tourism industry, the tourism and life service APP often just emphasize corporate goals but ignore user experience. For example, the classification of these APPs are messy, many well-known travel brands are implanted, making visitors waste their time on useless operation and information reading, and unable to find out the information they need directly and quickly. In addition, serious homogeneity exists in tourism and life service APP product. Therefore, how to strengthen the function of self-guided tour APP interface and customize the APP interface required by the tourists is a question worth exploring.

\section{B. Environment}

According to incomplete statistics, Guangdong, Beijing and Jiangsu rank the top three in terms of downloads of 
tourism and life service APP, this reflects that Internet market's activity will be different in different regions. In the city with more active Internet market, the competition of Internet market is great, and users will have higher requirement of the interaction and vision of the APP interface.

\section{Emotion}

Emotion factors in interface design refer to convey information and feeling to the users taking interface as carrier, so that emotional resonance can be generated between people and product. The generation and obtaining of such emotional resonance is filled with uncertainty. Most the previous studies pay more attention to availability, and transform availability information into design. Yet at present, more emphasis shall be paid to users' emotion and interactivity [5]. Only the products and interface that can make people generate emotional resonance are easy to be accepted by people.

\section{ANALYSIS OF SELF-GUIDED TOUR APP USER EXPERIENCE}

User experience design draws on the knowledge from such fields as sociology, design, and engineering technology, which is a research field of high comprehensiveness. [6] Through the investigation and analysis of targeted population, the model of self-guided tour APP user experience design level can be constructed through the following points: first is usefulness, achieve users' established target through function interface of APP, and usefulness is the base for APP to attract users and generating user experience; second is easy to use, users can use APP skillfully via the visual experience and interactive experience of APP, enabling users to achieve the goal at the fastest speed and improve use efficiency; third is friendliness, APP gives users the emotional experience, and feeling good about it is conducive to enhance user experience; fourth is vision, convey information to users via characteristics of visual symbols, generating psychological hints, making products produce a kind of attraction. The user experience design level model is as follows "Fig. 1".

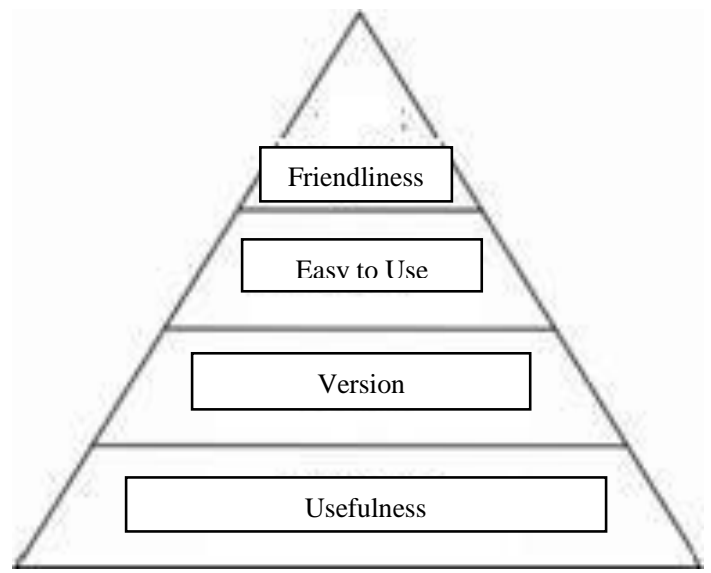

Fig. 1. The user experience design level model

\section{A. Usefulness}

Users download the APP are to meet certain requirements, for example, game type APP meets people's entertainment needs, dining type APP meets people's physical needs of food and clothing. Similarly, self-guided tour APP is to meet people needs of finding a local tour guide easily, to learn about the local tourism information and prices for a pleasant travel

\section{B. Easy to Use}

It is very important of self-guided tour APP to be easy to use. Users hope to have clear directivity while using the APP, which can meet their own needs without spending too much time. Ease to Use is to reduce users' cost of time and learning while they are using via APP interface and interaction design.

\section{Friendliness}

The emotional interface conveying friendliness is often subjective, arbitrary and ambiguous. [7] The self-guided tour APP should create an open and inclusive atmosphere for the users as much as possible, to reduce user's sense of distance. Make users feel to be served in terms of the interface and official documents and correspondence, rather than the supervisor-subordinate communication. For example: give corresponding friendly tips for every step of the operator, promoting exchanges between human and computer.

\section{Vision}

For self-guided tour APP, vision is the most direct way to communicate with users. In designing the interface, we should study users' behavior patterns and visual habits and other rules and follow the ergonomics, psychology and other disciplines, because in the process of conveying information by vision, color, graphics, size and location will become factors affecting user experience. However, in the process of interface design, designing out the combination way with unique visual symbols, can leave a deeper impression to the users while experiencing the product.

\section{SELF-GUIDED TOUR APP INTERFACE DESIGN BASED ON USER EXPERIENCE}

\section{A. Division of Self-guided Tour APP Interface Design}

As an Internet product, the mature products in APP Store shall be investigated and analyzed for the self-guided tour APP before design. Make generalization and conclusion from the APP's function, form and visual experience. Viewing from the APP in the current market, those products are short of communication with users, as they wish to attract users using brand but not to convey visual information, paying more user flows yet neglecting user experience. The design of a product is completed via the cooperation of several departments, with the division model of product design showing as below "Fig. 2 ". 


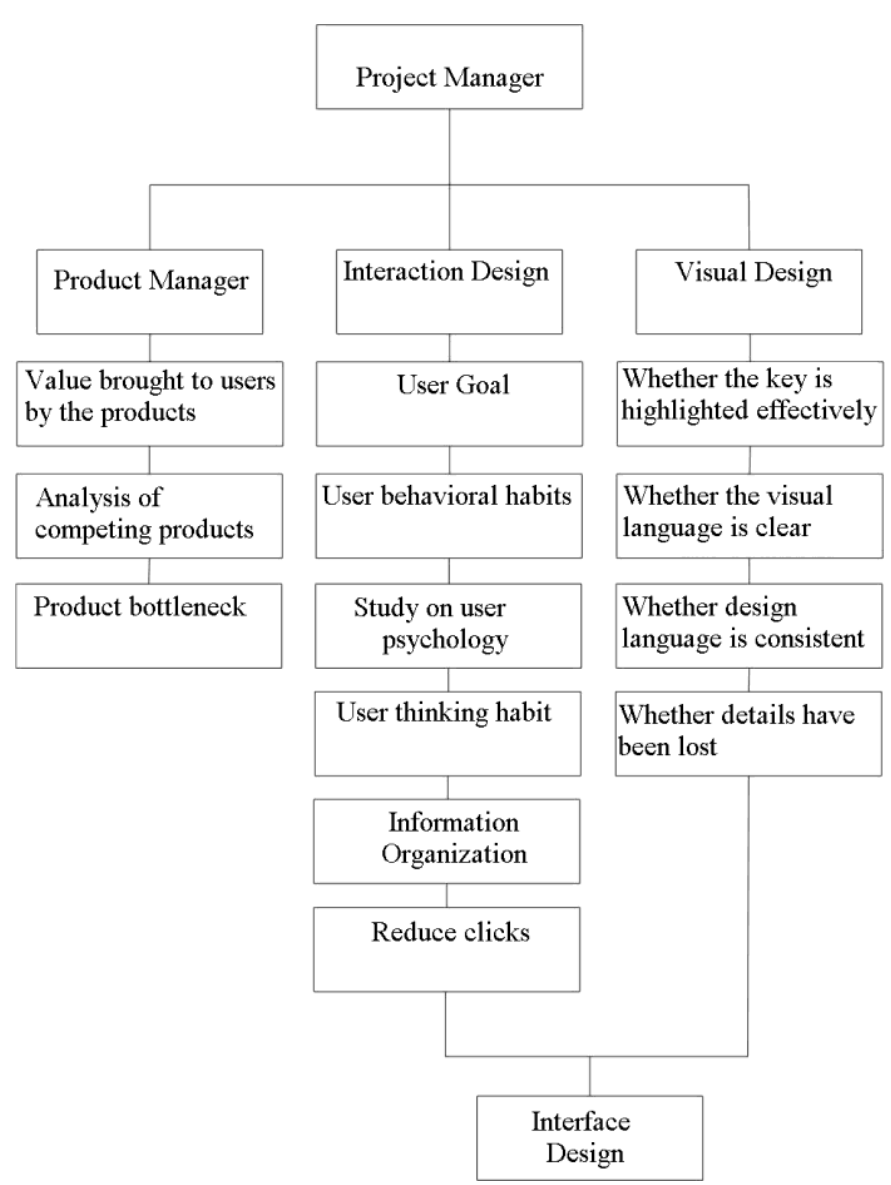

Fig. 2. The division model of product design

\section{B. Self-guided Tour APP Interface Design}

As can be seen from the division model, interface design not only includes the human-computer communication of interaction design under user behavior pattern, but also has the sensory experience of visual design. Take the independent designed self-guided APP - YOYO as an example.

1) Study and analyze user demand: Determine the user groups, conduct questionnaire and scenario analysis on them, and study user psychological behavior, to lay foundation for the user experience - oriented product interface design at late stage. According to preliminary incomplete statistics, when searching "tour guide" in Baidu, nearly fifty percent of the entries are about complaining tour guides. In the actual survey, communication with the target population has been conducted in the form of sharing stories, with the story sharing table ("Table I") shown as follows:

TABLE I. STORY SHARING TABLE

\begin{tabular}{|c|c|c|c|}
\hline \multirow{2}{*}{$\begin{array}{l}\text { Story } \\
\text { Content }\end{array}$} & \multirow{2}{*}{ Title } & Experience I & Experience II \\
\hline & & $\begin{array}{l}\text { Experience of the } \\
\text { best tourism } \\
\text { planning }\end{array}$ & $\begin{array}{c}\text { Experience of the } \\
\text { worst tourism planning }\end{array}$ \\
\hline \multirow{4}{*}{$\begin{array}{l}\text { Please } \\
\text { introduce } \\
\text { yourself } \\
\text { and share a } \\
\text { recent } \\
\text { tourism } \\
\text { experience } \\
\text { with us. }\end{array}$} & $\begin{array}{l}\text { Steps and } \\
\text { Motivati } \\
\text { on }\end{array}$ & $\begin{array}{l}\text { Relax in holiday; } \\
\text { friends have asked } \\
\text { for the places } \\
\text { suitable for } \\
\text { vacation; search the } \\
\text { tourism strategies } \\
\text { online }\end{array}$ & $\begin{array}{l}\text { Want a trip of Going } \\
\text { Now; interesting } \\
\text { places recommended } \\
\text { by friends; seeing } \\
\text { while walking }\end{array}$ \\
\hline & $\begin{array}{l}\text { Roles } \\
\text { and } \\
\text { Interactio } \\
\mathrm{n}\end{array}$ & $\begin{array}{l}\text { Discuss with } \\
\text { families about the } \\
\text { destination and } \\
\text { routes; search } \\
\text { information online }\end{array}$ & $\begin{array}{l}\text { Discuss with friends } \\
\text { traveling together } \\
\text { about where to go } \\
\text { upon arriving at the } \\
\text { destination; search } \\
\text { information } \\
\text { temporarily } \\
\text { mobile phones }\end{array}$ \\
\hline & $\begin{array}{l}\text { Tools \& } \\
\text { Use }\end{array}$ & $\begin{array}{l}\text { Mobile phone, } \\
\text { applications, } \\
\text { notebook }\end{array}$ & $\begin{array}{l}\text { Mobile phone, } \\
\text { applications }\end{array}$ \\
\hline & $\begin{array}{l}\text { Environ } \\
\text { ment }\end{array}$ & $\begin{array}{l}\text { Plan at home using } \\
\text { computer, mobile } \\
\text { phone } \\
\text { notebook }\end{array}$ & $\begin{array}{l}\text { Plan temporarily on } \\
\text { the car only using } \\
\text { mobile phone }\end{array}$ \\
\hline
\end{tabular}

In sharing stories, we can clearly learn about travelers motivation and their application of environment and tools. Generally, people's motivation of a travel is out of the consideration of relaxing and broadening their horizons. When travelers generate a motivation of traveling and make plan for it, most of them will use the APP and consult people around them. The routes will often be obtained from the Internet, thereby improving the efficiency. The interaction model is established based on investigation on people's behavior patterns prior to traveling "Fig. 3". 


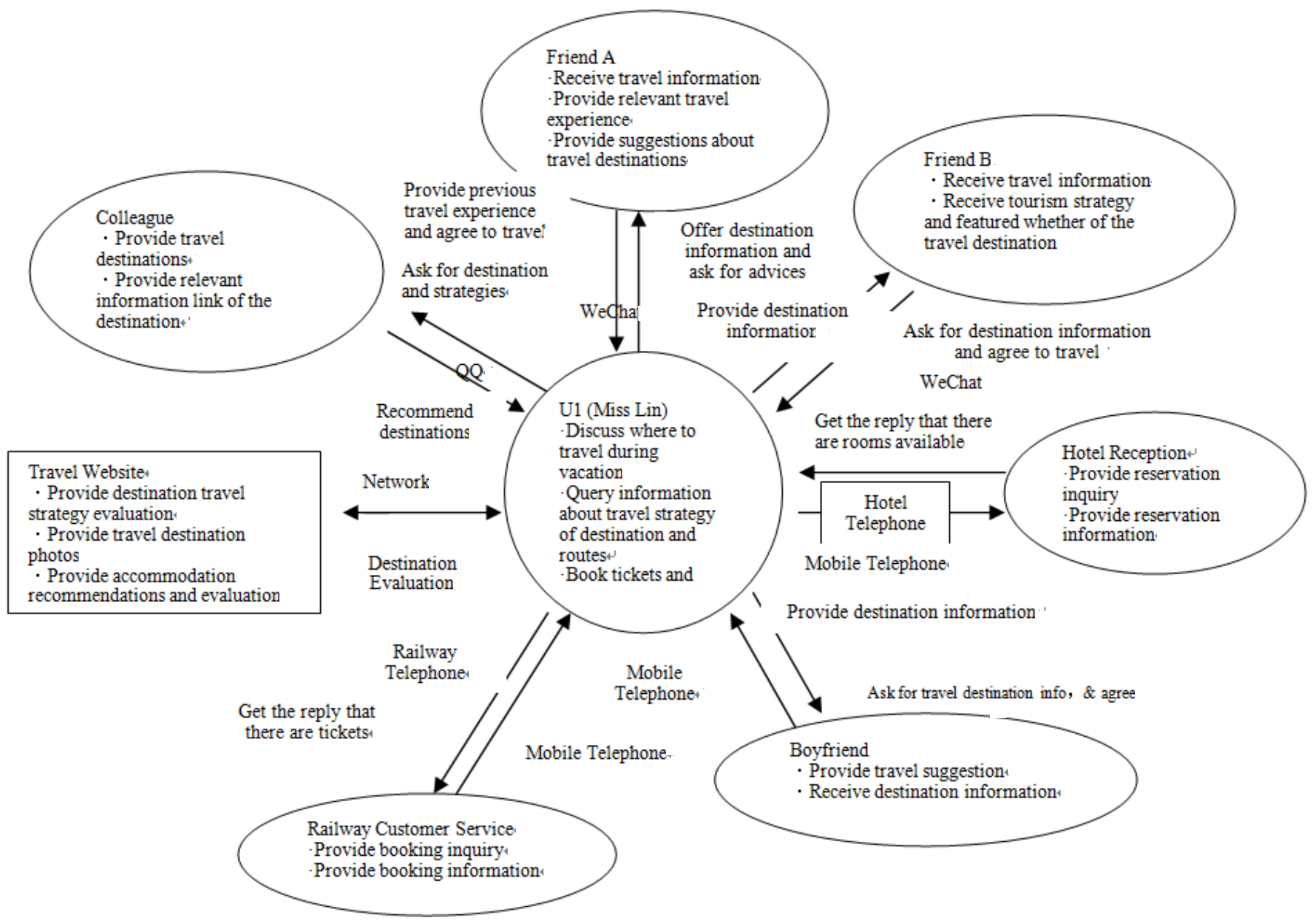

Fig. 3. People's behavior patterns prior to traveling

It can be seen from the construction and analysis of the interaction model that, when user has travel needs, he/she will communication with different people to obtain information. However, the usefulness of information cannot be guaranteed with narrow scope and long time for obtaining information, making the cost for obtaining information higher. The target prototype is determined based on the interaction model "Fig. 4", and study and analysis have been conducted on its behavior pattern "Table II", and find that, the experienced travelers will use network resources to collect relevant information of the travel destinations while planning. But there are too much information displayed on tourism APP interface, so users are unable to find the useful information and cannot determine the authenticity of the information. Such situation would delay the traveler's itinerary, and when travelers collect travel information using APP again, it will cost them more time to make information screening.

Through the above investigation and analysis, it can seen that, for travelers not with a group, they need to find someone who are familiar with the travel destination to assist their preparation and screening of travel information using tourism APP, to ensure the information is real and effective. And they hope to find out other visitors' comments on and feelings about the tourist destinations in the APP, for the convenience of users to compare and screen the tourist destinations. 


\section{TABLE II. ANALYSIS TABLE OF USER BEHAVIOR PATTERN}

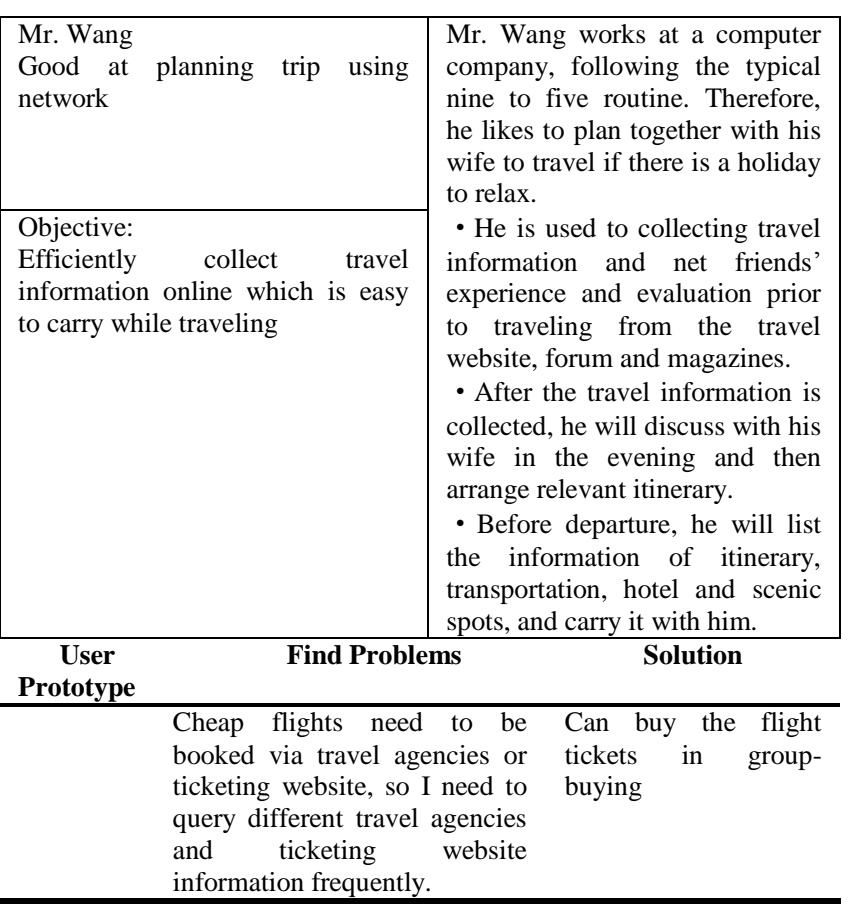

\begin{tabular}{|c|c|c|}
\hline \multirow[t]{4}{*}{$\begin{array}{l}\text { Mr. Wang } \\
\text { Good at } \\
\text { planning } \\
\text { trip using } \\
\text { network }\end{array}$} & $\begin{array}{l}\text { Find some information queried } \\
\text { previously to be slightly } \\
\text { inaccurate, and I need to spend } \\
\text { time to modify my itinerary. }\end{array}$ & $\begin{array}{l}\text { Local service } \\
\text { personnel provide } \\
\text { explanation } \\
\text { stationary point } \\
\text { Correct the wrong } \\
\text { travel information } \\
\text { online }\end{array}$ \\
\hline & $\begin{array}{l}\text { For fear of trip delay due to } \\
\text { getting lost, I will prepare more } \\
\text { copies of the maps and } \\
\text { transportation guide. }\end{array}$ & GPS + Siri \\
\hline & $\begin{array}{l}\text { It will cost much of my time } \\
\text { after work to plan the trip, so I }\end{array}$ & $\begin{array}{l}\text { Lazy package of travel } \\
\text { itinerary }\end{array}$ \\
\hline & $\begin{array}{l}\text { will follow the route of travel } \\
\text { talent online. }\end{array}$ & $\begin{array}{l}\text { Self-guided travel } \\
\text { commissioner }\end{array}$ \\
\hline
\end{tabular}

2) Architecture Design. Architecture model has determined the basic functions, preferences and key features: Architecture design is the interface process design. Sort out the process of users' using of APP, arrange the order of the functions and interfaces that users use to complete the fixed goal while using APP, and connect them "Fig. 4".

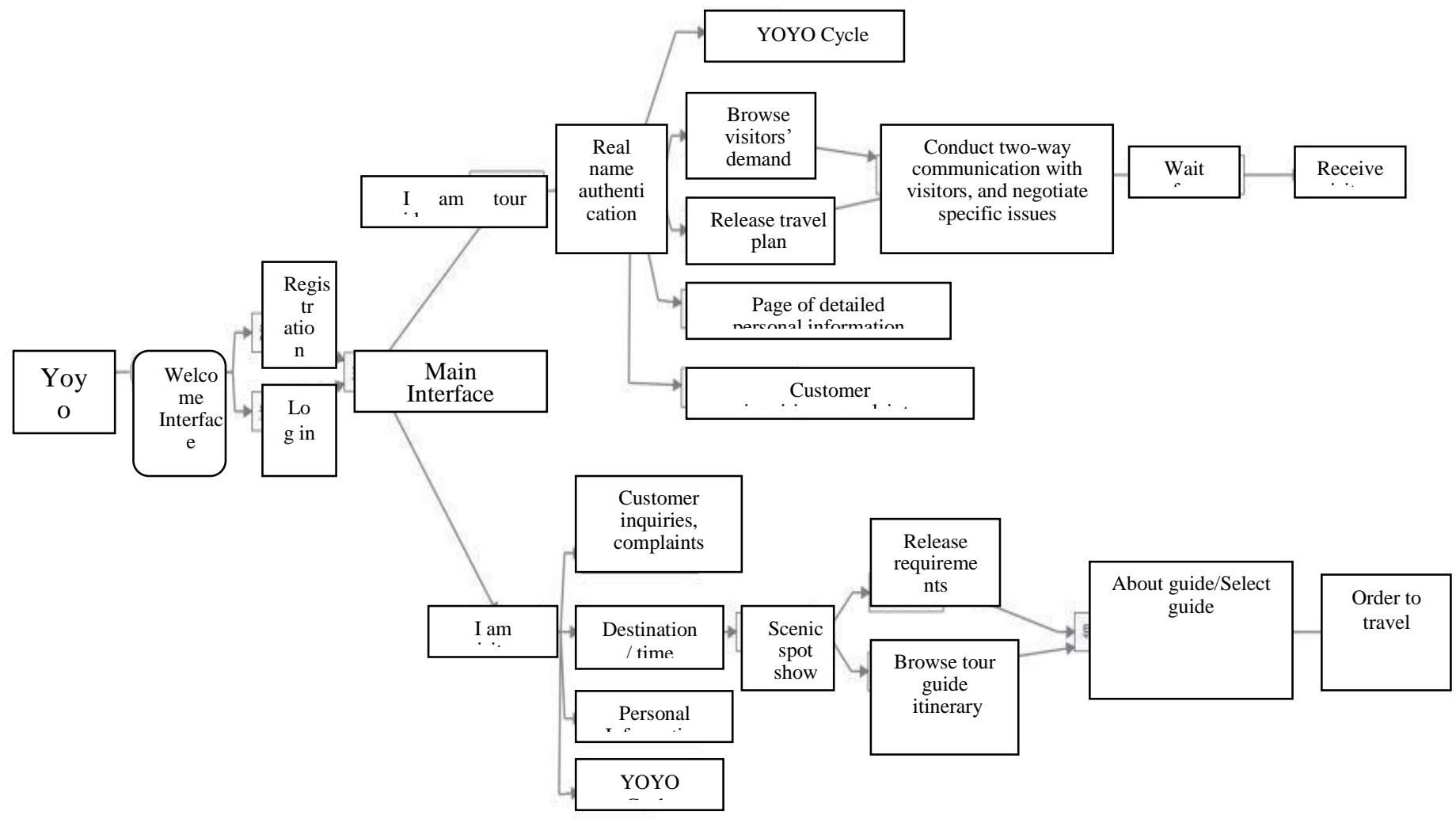

Fig. 4. The interface of the APP 
The wireframe describes logical order of the information based on hierarchy of information, explains the relation and difference between interface and interface, providing foundation for imaging of interface design. It can be seen from conception of this part, that the steps of using APP are simplified, strengthening the usability of APP, and meeting the needs of users.

3) Prototype Design. Set up the preliminary APP prototype based on users' using process of APP of architecture design: In the prototype interaction, enable users to strengthen the human-computer communication while using the interface through studying of visitors' behavior, and enhance the interaction efficiency. For example, users can use the APP without learning, visitors would like to see timely information updates and can find it with the fastest speed, the clicks can reduced while operating, users can get reply timely when they make information feedback, multiple task interfaces can exist simultaneously while using self-guided tour APP, meet visitors' requirements of data comparing while customizing tour guides "Fig. 5". The interaction between APP interface and users shall be considered comprehensively for APP interface design under the perspective of user experience, and such interaction will be conducted via various carrier, medium and interface carrying information. [8] The design of APP prototype interaction can effectively improve the efficiency of users, bringing good interactive experience to the users, which is conducive to enhance the user experience.
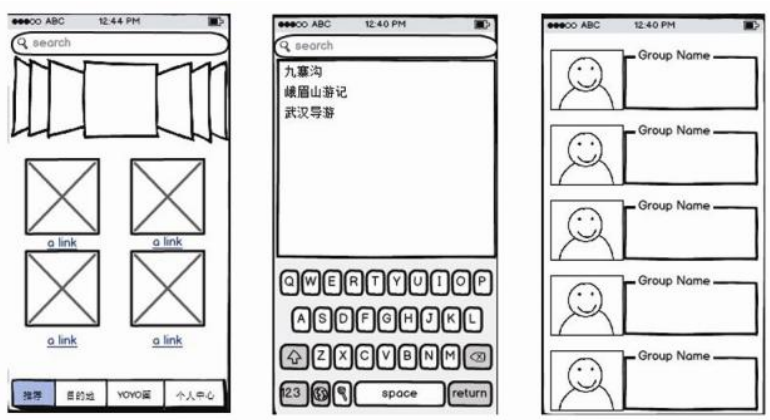

Fig. 5. The interface of self-guided tour APP

4) Visual Design. Vision is the part that first contacts with users' product directly: In the context that tourism APP homogenization is serious within the network market, good visual language expression can attract users, create a unique visual symbol of the product, which can strengthen product's recognizability. Designers should make the identifying interface design based on products' style positioning and establishing a friendly feeling for APP and users. While conducting visual design in the interface, arrange the order of information, update the tourism information required by the visitors timely and place it at the vision center. The order arrangement of information enables the users to find out information they want with the fastest speed, improving users' efficiency.

\section{Examples of Self-guided Tour APP Interface Design Application}

Designers shall transfer the user model and demand to system interface, including text, graphics, images, colors, layout, animation, etc., and communication between user and product shall be made by virtue of interface. [10]

1) Due to the popularity of mobile phones with large screen, operating blind area shall be avoided, to make information screening and effective arrangement. Leave appropriate blank on the screen, reduce users' clicks and increase the sliding block "Fig. 6".

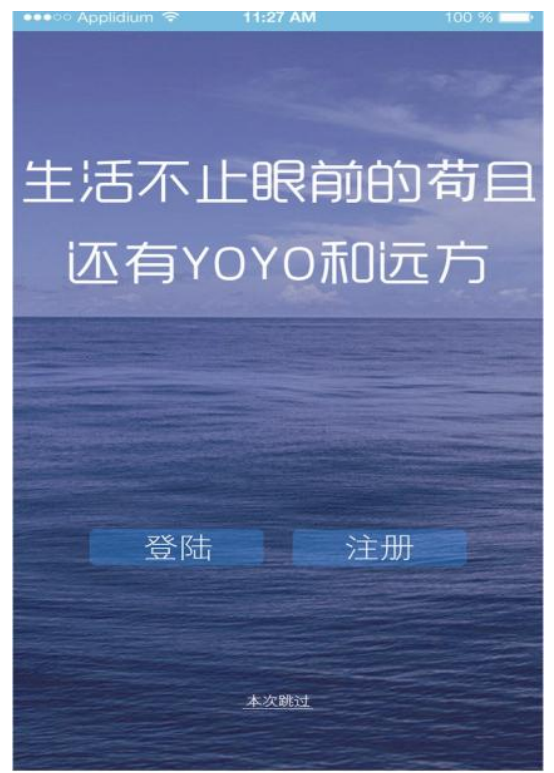

Fig. 6. The interface of the APP

2) The more vivid emotional design. The market of APP application stores in the Internet market is more and more refined. But the tour and life service APP product homogeneity is still very serious, so users' demand shall be customized against this problem, integrating the feeling interface into functional interface.

3) Standardization. The mobile phone market is currently occupied by Android and iOS systems. If the self-guided tour APP follows the platform specifications of these two systems, it will greatly reduce user's learning costs, enhancing app's ease of use, making it easier for users to accept it, and increasing user loyalty. For example, use a translucent baseplate, relate the usage scenarios and differentiate the contents; use the system font to ensure legibility and readability. Take the following figure as an example: the Apple Founder line is adopted for the font and the translucent baseplate is used "Fig. 7". 


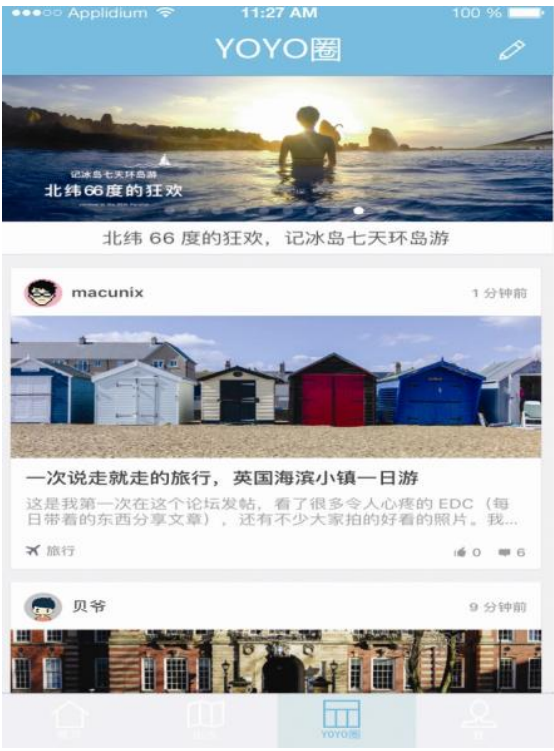

Fig. 7. The interface of the APP

4) Dynamic effects refer to the body language of APP. Dynamic effects can attract the user's attention. When the display areas are same, user's attention will follow the dynamic efficiency - color - shape respectively. With respect to the size and length of time, we can divide the dynamic effects into four categories: first, large area long time, for the page introduction or product video promotion; the second is large area short time, for the interface switching; the third is small area short time, having certain role in guiding; small area long time, attract users' attention for a long time without interfering the receipt of other information. Take the following figure as an example, all the three interfaces use the dynamic effects with small arrows, playing a leading role, without preventing the users from obtaining information "Fig. 8".
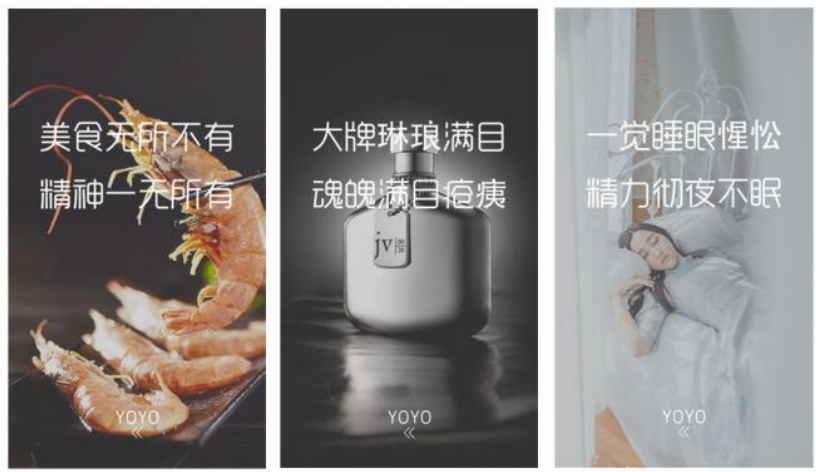

Fig. 8. The interface of the APP

5) Data visualization. Large number of data will appear in self-guided tour APP, such as weather conditions, the flow of people, tour guides' basic information, the number of reception, reception evaluation and so on. To make the expression of data more abundant, transform the dull figures into color block and graphics, such as pie shape, curve and pattern, making it easier for users to read the information in the use of the product, and increasing users' good feeling toward the products. The tour guide evaluation of the following figure show the evaluation degree of tour guide in the form of icon, which is an example of data visualization "Fig. 9".

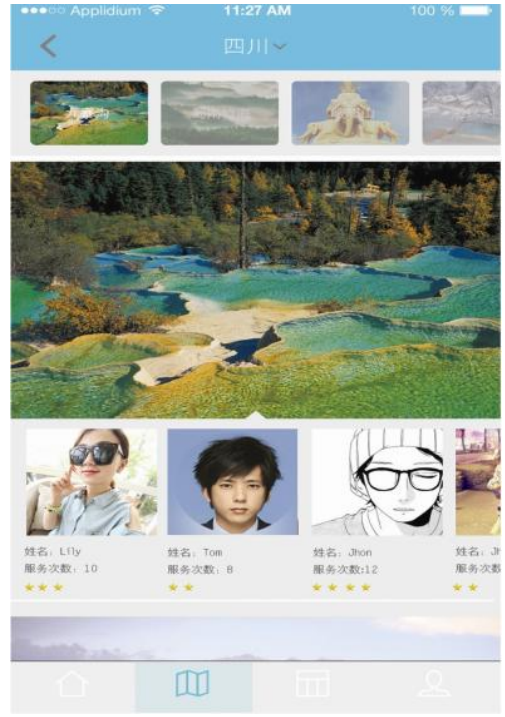

Fig. 9. The interface of the APP

6) Color. Use a small amount of color can obtain a clean interface. Taking the following figure as an example, the product with small amount of color has the identifiability, which is convenient to emphasize critical information. Too rich color or messy arrangement, do not follow the visual law will cause trouble to users "Fig. 10".
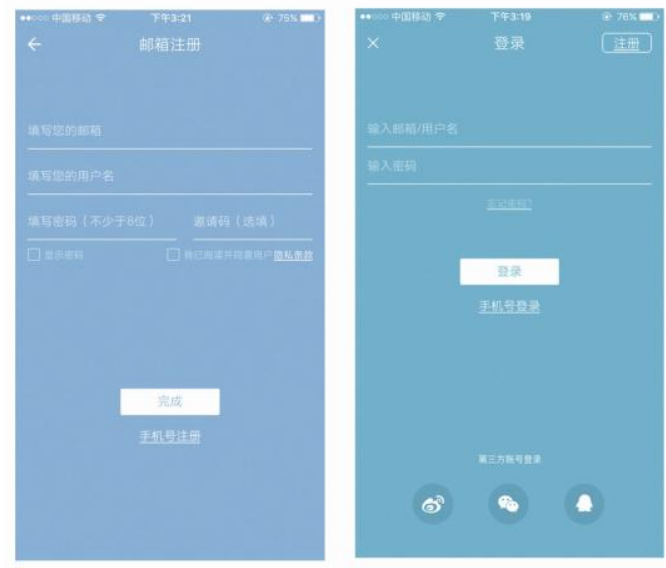

Fig. 10. The interface of the APP

\section{CONCLUSION}

With the increasing emphasis on tourist APP user experience, the development of tourist APP interface design is not just limited to meet users' function demand and aesthetic needs, but also shall study the human-computer interaction process in-depth in terms of users' psychological behavior and thinking habits, etc., thus to obtain users' recognition with good interactive experience. In the research practice of selfguided tour APP interface design in the future, the more indepth study on interactive design architecture and model under 
the perspective of user experience will be conducted based on this in the future, to provide more theoretical basis for enhancement of user experience of self-guided tour APP.

\section{REFERENCES}

[1] Pine II BJ, Gilmone .JH The experience economy:work is theathe \& every business a stage [M].Boston Harvard Business School Press 1999

[2] Red storm J.Towards user design? On the shift from object to user as the subject of design [J].Design studies. 2006. 27(2): 123-139

[3] Zhang Xi. China to Open Freelance Tour Guide and Tour Guide Certificate to be Valid for Lifetime [N]. People's Daily, 2016-01-29

[4] Li Junjie, Sun Shouqian, Xu Xiaofeng. Aspects of Interface Design $[\mathrm{C}] / / 2005$ International Industrial Design Seminar and the Tenth National Industrial Design Annual Conference, Wuhan, 2005: 614618.

[5] Chamorro-Koe M, Popovie V, Emmison M. Human experience and product usability: principles to assist the design of user-product interactions[J]. Applied Ergonomics 2009, 40(4): 648-656

[6] Luo Shijian, Gong Rongrong and others. Handheld Mobile Device Software Interface Design facing User Experience [J]. Journal of Computer-Aided Design and Computer Graphics, 2010, 22 (06): 1034 - 1041.

[7] Luo Shijian, Pan Yunhe, Zhu Shangshang. Implicit Expression based on Graphic Thought in Product Design [J]. Journal of Mechanical Engineering, 2007.43 (6):93—98.

[8] Qin Jingyan. Big Interactive Design in Big Data Era [J]. Packaging Engineering, 2015, 36( 08) : $01-05$.

[9] Tang Lin, Chang Yu. Study on User-centered Handheld Mobile Device APP Interface Design [J]. Shandong Social Science, 2015, 12: 97-99.

[10] Dong Shihai, Dai Guozhong, Wang Jian and others. Human-computer Interaction and Multi-channel User Interface [M]. Beijing: Science Press, 1999. 